\title{
New interpretation of the role of water balance in an extended Budyko hypothesis in arid regions
}

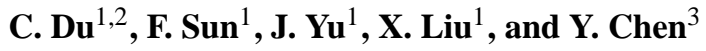 \\ ${ }^{1}$ Key Laboratory of Water Cycle and Related Land Surface Processes, Institute of Geographic Sciences and Natural \\ Resources Research, Chinese Academy of Sciences, Beijing 100101, China \\ ${ }^{2}$ University of Chinese Academy of Sciences, Beijing, 100049, China \\ ${ }^{3}$ State Key Laboratory of Desert and Oasis Ecology, Xinjiang, Institute of Ecology and Geography, Chinese Academy of \\ Sciences, Urumqi, 830011, China \\ Correspondence to: F. Sun (sunfb@igsnrr.ac.cn), J. Yu (yujj@igsnrr.ac.cn)
}

Received: 31 August 2015 - Published in Hydrol. Earth Syst. Sci. Discuss.: 27 October 2015

Revised: 27 December 2015 - Accepted: 6 January 2016 - Published: 21 January 2016

\begin{abstract}
The Budyko hypothesis (BH) is an effective approach to investigating long-term water balance at large basin scale under steady state. The assumption of steady state prevents applications of the BH to basins, which is unclosed, or with significant variations in root zone water storage, i.e., under unsteady state, such as in extremely arid regions. In this study, we choose the Heihe River basin (HRB) in China, an extremely arid inland basin, as the study area. We firstly use a calibrated and then validated monthly water balance model, i.e., the $a b c d$ model, to quantitatively determine annual and monthly variations of water balance for the sub-basins and the whole catchment of the HRB, and find that the roles of root zone water storage change and that of inflow from upper sub-basins in monthly water balance are significant. With the recognition of the inflow water from other regions and the root zone water storage change as additional possible water sources to evapotranspiration in unclosed basins, we further define the equivalent precipitation $\left(P_{\mathrm{e}}\right)$ to include local precipitation, inflow water and root zone water storage change as the water supply in the Budyko framework. With the newly defined water supply, the Budyko curve can successfully describe the relationship between the evapotranspiration ratio and the aridity index at both annual and monthly timescales, whilst it fails when only the local precipitation being considered. Adding to that, we develop a new Fu-type Budyko equation with two non-dimensional parameters $(\omega$ and $\lambda$ ) based on the deviation of Fu's equation. Over the annual timescale, the new Fu-type Budyko equation developed here has more or less identical performance to Fu's original
\end{abstract}

equation for the sub-basins and the whole catchment. However, over the monthly timescale, due to large seasonality of root zone water storage and inflow water, the new Fu-type Budyko equation generally performs better than Fu's original equation. The new Fu-type Budyko equation ( $\omega$ and $\lambda$ ) developed here enables one to apply the $\mathrm{BH}$ to interpret regional water balance over extremely dry environments under unsteady state (e.g., unclosed basins or sub-annual timescales).

\section{Introduction}

The Budyko hypothesis (hereafter $\mathrm{BH}$ ) was postulated by a Russian climatologist, Mikhail Ivanovich Budyko, to analyze regional differences in long-term annual water and energy balance (Budyko, 1948). The BH's mean annual water balance is described by the evapotranspiration ratio and the climate aridity index. The BH becomes an effective approach to investigating the influence of climate change on mean annual runoff and evapotranspiration (Donohue et al., 2011; Xiong et al., 2014). There are various equations to describe the BH. Some empirical equations without parameters were proposed by Schreiber (1904), Ol'dekop (1911), Budyko (1948) and Pike (1964) (see Table 1). These equations explicitly include climate variations (radiation, precipitation, evapotranspiration and air temperature) and do not deal with recently recognized important catchment properties, such as characteristics of groundwater system, vadose zone properties, vegetation. Hence, attempts have been made 
to introduce physical parameters in these empirical equations (Mezentsev, 1955; Fu, 1981; Milly, 1993; Zhang et al., 2001; Yang et al., 2007, 2008). These physical parameters are a collection of myriad catchment characteristics (topography, vegetation, soil, and groundwater, etc.) and are therefore difficult to measure (Gerrits et al., 2009). These equations with a single parameter, however, provide the flexibility of using the $\mathrm{BH}$ over long-term timescales.

The BH assumes steady-state conditions. Firstly, the studied basin must be natural and closed, which means that the local precipitation is the only water source to the evapotranspiration. Recently, the $\mathrm{BH}$ has been widely used to investigate the interannual variability of precipitation partitioning (Gerrits et al., 2009), separation of runoff trends (H.-Y. Li et al., 2014; Xiong et al., 2015), evapotranspiration change (Savenije, 1997) and water storage change (Istanbulluoglu et al., 2012; Gao et al., 2014). These studies show that hydrological processes have been greatly affected by the climate change and intensive change of land cover owing to human activities. These human activities such as urbanization, withdrawing groundwater, hydraulic engineering, deforestation etc. are significantly changing natural hydrological cycle and breaking the original water balance to form a new balance under the new hydroclimatic conditions. For example, the transferring water becomes the new water source of the basin to evapotranspiration due to the implemented interbasin water transfer project (Bonacci and Andric, 2010). In dry regions, croplands expanded with irrigation, which increased water availability for evapotranspiration (Gordon et al., 2005). Land use/cover changes have also caused the change of runoff (J. Li et al., 2014). Nowadays, most of the inhabited basins have been developed or disturbed by large-scale human actives. Therefore, lots of basins were no longer closed or natural, and the relationship between annual evapotranspiration ratio and potential evapotranspiration ratio hardly meets the first condition of the $\mathrm{BH}$, which presents a great challenge in applying the $\mathrm{BH}$ in unclosed basins.

Secondly, water storage change can be assumed to be negligible at the basin scale and at long-term timescale. However, over finer temporal scales, it becomes increasingly concerned of the importance of water storage in water balance in the Budyko framework. For example, Wang et al. (2009) found that the inter-annual water storage change should be considered due to the hysteresis response of the base flow to the inter-annual precipitation change in Nebraka Sand Hills. Zhang et al. (2008) considered the impacts of soil water and groundwater storage and developed a monthly water balance model based on the BH with application in 265 catchments in Australia. Yokoo et al. (2008) highlighted the importance of soil water storage change in determining both annual and seasonal water balances. Wang (2012) evaluated changes in inter-annual water storage at 12 watersheds in Illinois using the field observation of long-term groundwater and soil water and found that the impact of inter-annual water storage changes on the water supply in the $\mathrm{BH}$ need to be consid- ered. Chen et al. (2013) defined the difference between rainfall and storage change as effective precipitation to develop a seasonal model for construction long-term evapotranspiration. Therefore, water storage change should be taken into account as the important part of the steady-state assumption of the BH (Zhang et al., 2008).

In summary, it has been more and more recognized that water systems are no longer natural to different extents (Sivapalan et al., 2011). Hence, it presents a great challenge to apply the BH to unsteady-state conditions (unclosed basins or intense water storage changes). The BH has been widely applied to mild arid basins with precipitation of $300-400 \mathrm{~mm}$ and aridity index of less than, for example, 5, such as over northern China (Yang et al., 2007), the southwestern regions of MOPEX catchments (Gentine et al., 2012; Carmona et al., 2014) and the west of Australia (Zhang et al., 2008). However, it is rare to apply the $\mathrm{BH}$ in extremely arid environments (say, the aridity index over 5), where water systems are typically unclosed with intense human interference and irrigation. For example, rivers in the arid region of northwestern China are typically from upper mountains with little human interference, and flow through middle regions with intensive irrigation and human interferences and finally into extremely dry desert plains. To investigate it in more detail, we choose the Heihe River basin (HRB), the second largest arid inland basin in northwestern China (mean annual aridity index $=10$ ). Being an inland basin, the HRB consists of six sub-basins with different landscapes and climate conditions, where the upper mountainous basins are closed and natural with little human interference (long-term mean annual water storage change approaches zero), the middle basins are arid and intensively irrigated plain with strong human interference (mean annual evapotranspiration is higher than the local precipitation), and the lower basin is extremely dry Gobi desert plain without any runoff flowing out (evapotranspiration is mainly the local precipitation; mean annual evapotranspiration approaches mean annual precipitation). In this study, our aim is threefold. (1) We first test whether the BH is applicable to the unsteady-state condition in extremely arid basins. (2) If not, we in further improve the original $\mathrm{BH}$ by including observed water balance. (3) We finally extend the applicability of the $\mathrm{BH}$ at unclosed basin scale and annual or monthly timescales.

\section{Theory and method}

\subsection{Annual and monthly water balance analysis}

In the original $\mathrm{BH}$, the basin is a natural hydrologic unit, and the only possible water source for evapotranspiration is the local precipitation. The annual or monthly water balance equation can be written as

$P=\mathrm{ET}+Q_{\text {out }}-Q_{\text {in }}+\Delta S+\Delta G$ 
Table 1. Different Budyko equations for the mean annual water-energy balance.

\begin{tabular}{|c|c|c|c|}
\hline Number & Equation & Parameter & Reference \\
\hline 1 & $\varepsilon=1-\exp (-\varphi)$ & None & Schreiber (1904) \\
\hline 2 & $\varepsilon=\varphi \tanh (1 / \varphi)$ & None & Ol'dekop (1911) \\
\hline 3 & $\varepsilon=\{\varphi[1-\exp (-\varphi)] \tanh (1 / \varphi)\}^{0.5}$ & None & Budyko $(1958,1974)$ \\
\hline 4 & $\varepsilon=\left(1+\varphi^{-2}\right)^{-0.5}$ & None & Pike (1964) \\
\hline 5 & $\varepsilon=\left(1+\varphi^{-\alpha}\right)^{-1 / \alpha}$ & $\alpha$ - calibration factor & $\begin{array}{l}\text { Mezentsev (1955); Chouldhury (1999); } \\
\text { Yang et al. (2008) }\end{array}$ \\
\hline 6 & $\varepsilon=\frac{1+\omega \varphi}{1+\omega \varphi+\varphi^{-1}}$ & $\begin{array}{l}\omega-\text { coefficient of } \\
\text { vegetation and water supply }\end{array}$ & Zhang et al. (2001) \\
\hline 7 & $\varepsilon=\frac{\exp [\gamma(1-1 / \varphi)]-1}{\exp [\gamma(1-1 / \varphi)]-\varphi^{-1}}$ & $\begin{array}{l}\gamma-\text { the ratio of the soil water } \\
\text { storage capacity to precipitation }\end{array}$ & Milly (1993); Porporato et al. (2004) \\
\hline 8 & $\varepsilon=1+\varphi-\left(1+\varphi^{\omega}\right)^{1 / \omega}$ & $\omega-$ a constant of integration & Fu (1981); Zhang et al. (2004); Yang et al. (2007) \\
\hline
\end{tabular}

Note: $\varepsilon=\mathrm{ET} / P$ evapotranspiration ratio (the ratio of mean annual evapotranspiration to mean annual precipitation); $\varphi=\mathrm{ET}_{0} / P$, aridity index (the ratio of mean annual potential evapotranspiration to mean annual precipitation).

where $P$ is the annual or monthly precipitation $(\mathrm{mm})$; ET is the sum of soil evaporation and vegetation transpiration (mm); $Q_{\text {out }}$ is the outflow away from a basin (mm); $Q_{\text {in }}$ is the channel inflow that is from the upper basin and/or inter-basin water transfer (mm); $\Delta S$ is the root zone water (namely, soil water) storage change, $(\mathrm{mm})$; and $\Delta G$ is the groundwater storage change (mm).

Because of human interferences (land cover change, dams, irrigation and other withdrawals) to the hydrologic system worldwide, the water supply to evapotranspiration in a basin has changed. Local groundwater and root zone water and external water transfer also become new possible water sources. However, that new non-ignorable part of available water for evapotranspiration has yet been explicitly considered in the Budyko framework in an unclosed basin. More specifically, the inflow or/and inter-basin water transfer may affect the available water for evapotranspiration largely. By considering that, here we rearrange Eq. (1) as $P+Q_{\text {in }}-\Delta S=$ $\mathrm{ET}+Q_{\text {out }}+\Delta G$ the available water for evapotranspiration in Eq. (1) as

$P_{\mathrm{e}}=P+Q_{\text {in }}-\Delta S$,

where the total water supply to evapotranspiration in an unclosed basin is denoted as $P_{\mathrm{e}}$ and, for simplicity, $P_{\mathrm{e}}$ hereafter is defined as the equivalent precipitation of the $\mathrm{BH}$ at finer timescales. If $\Delta S$ is more than zero, it means the surplus water is stored in the vadose zone, which should be deducted from the water sources. If $\Delta S$ is less than zero, it means root zone water contributes to the evapotranspiration consumption. Note that the change of groundwater storage $(\Delta G)$ is the result of the exchange between groundwater and baseflow and is not directly interacted with evapotranspiration, so that $\Delta G$ is not included into the defined $P_{\mathrm{e}}$ in Eq. (2). It will be discussed in the results section.

\subsection{Budyko hypothesis model at annual and monthly scales}

As discussed above, in the original Budyko framework, the water supply to land evapotranspiration is mean annual precipitation, and the energy supply to land evapotranspiration is estimated by mean annual potential evapotranspiration. The general Budyko equation can be written as

$$
\frac{\mathrm{ET}}{P}=F\left(\frac{\mathrm{ET}_{0}}{P}\right)
$$

where $\frac{\mathrm{ET}}{P}$ is the evapotranspiration ratio; $\frac{\mathrm{ET}_{0}}{P}$ is the aridity index. $F$ is the function to be determined. The general analytical solution to Eq. (3) over mean annual timescales is derived by $\mathrm{Fu}$ (1981) and is written as follows:

$\mathrm{ET}=\mathrm{ET}_{0}+P-\left(\mathrm{ET}_{0}^{\omega}+P^{\omega}+C\right)^{1 / \omega}$

where $\omega$ is the parameter, which reflects the integrated effects of soil, vegetation and topography on separating the ET from the local precipitation (Sun, 2007). If the local precipitation is zero, evapotranspiration approaches zero due to no available water; $C$ is zero constant. Note that another form of the BH is also given by Mezentsev (1955) (later, Choudhury, 1999, and Yang et al., 2008), which is, in fact, identical to Fu's equation (Zhou et al., 2015) with the parameters linearly related $\left(R^{2}=0.9997\right)$ (Sun, 2007).

Water balance analysis in Sect. 2.1 concludes that the water supply in the $\mathrm{BH}$ under the unsteady-state condition is the equivalent precipitation instead of the local precipitation. So the annual (or monthly) evapotranspiration ratio is redefined as the ratio of annual (or monthly) evapotranspiration and equivalent precipitation, and the annual (or monthly) aridity index is redefined as the ratio of annual (or monthly) potential evapotranspiration and equivalent precipitation. They are 


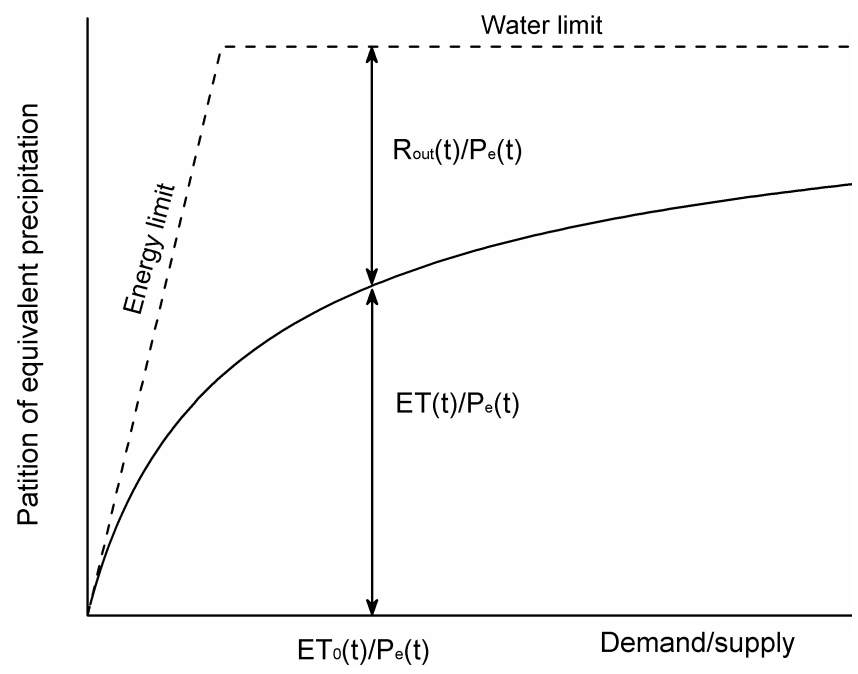

Figure 1. A schematic diagram of the $\mathrm{BH}$ under the unsteady-state condition.

described as follows:

$\frac{\mathrm{ET}}{P_{\mathrm{e}}}=\frac{\mathrm{ET}}{P+Q_{\text {in }}-\Delta S}$,
$\frac{\mathrm{ET}_{0}}{P_{\mathrm{e}}}=\frac{\mathrm{ET}_{0}}{P+Q_{\text {in }}-\Delta S}$.

If the equivalent precipitation can be evaporated by enough available energy $\left(\mathrm{ET}_{0} / P_{\mathrm{e}} \rightarrow \infty\right)$, then annual (or monthly) evapotranspiration may approach annual (or monthly) precipitation $\left(\mathrm{ET} / P_{\mathrm{e}} \rightarrow 1\right)$. Such a condition is moistureconstrained. While, if the available energy to evaporate the annual (or monthly) precipitation is limited $\left(\mathrm{ET}_{0} / P_{\mathrm{e}} \rightarrow 0\right.$ ), the annual (or monthly) evapotranspiration may approach annual (or monthly) potential evapotranspiration (ET $/ \mathrm{ET}_{0} \rightarrow$ 1). Such condition is energy-constrained. Figure 1 describes partitioning of the equivalent precipitation into evapotranspiration, streamflow and groundwater storage change, which follows the BH. The Budyko equation under unsteady-state assumption can be written as

$\frac{\mathrm{ET}}{P_{\mathrm{e}}}=F\left(\frac{\mathrm{ET}_{0}}{P_{\mathrm{e}}}\right)$

Under the unsteady-state conditions for a region, when the local precipitation in the origin Fu's equation is zero, evapotranspiration may not be zero due to other water sources (e.g., inter-basin water transfer), so following the derivation of Fu (1981). Equation (4) can be rewritten as

$\frac{\mathrm{ET}}{P_{\mathrm{e}}}=1+\frac{\mathrm{ET}_{0}}{P_{\mathrm{e}}}-\left[1+\left(\frac{\mathrm{ET}_{0}}{P_{\mathrm{e}}}\right)^{\omega}+\lambda\right]^{1 / \omega}$,

where $\omega$ and $\lambda$ are two fitting parameters and both nondimensional. $\omega$ has been widely discussed and is greater than 1 (Fu, 1981; Yang et al., 2007). By meeting the constraints formed by the $\mathrm{BH}$, we can derive that $\lambda \geq-1$ (see the Appendix A). When $\lambda=0$ (Fig. 2a), Eq. (8) is the same as Fu's equation in its original form (Fu, 1981; Zhang et al., 2004; Yang et al., 2007). For $\lambda$ becomes positive, e.g., 1, the lower end of the Budyko curve adjusts to the right (Fig. 2b, c). And $\lambda=-1$ sets up the upper theoretical constraint of the Budyko curve (Fig. 2c, d). We speculated that $\lambda$ may be related to rainfall intensity or hydraulic conductivity of soil.

\subsection{A monthly water balance model: $a b c d$ model}

Regional evapotranspiration and soil water cannot be measured directly and they are usually provided by monthly water balance models. Monthly water balance models were first developed in the 1940s. From that, many models have been developed in hydrological studies, such as the $T$ model, $T \alpha$ model, $P$ model, $a b c$ model and $a b c d$ model, that are often popular due to the relatively simple structure and fewer parameters (Fernandez et al., 2000).

Among these monthly models, the abcd model was proposed by Thomas (1981) has been widely applied to assess regional water resources due to its explicit model structure and only four parameters, of which two parameters pertain to runoff characteristics and the other two relate to groundwater sound physical meanings. Actually, the abcd model was originally developed and applied for monthly water balance instead of annual (Alley, 1984). Moreover, Savenije (1997) has verified that the $a b c d$ model to derive expressions for the evapotranspiration ratio has better agreement with observations than Budyko-type curves. Inputs to the $a b c d$ model are monthly precipitation and potential evapotranspiration. Outputs include monthly runoff (direct and indirect), soil water storage, groundwater storage and actual evapotranspiration. Therefore, this study employs the abcd model to provide monthly actual evapotranspiration and soil water storage.

The partitioning of monthly precipitation $P_{t}$ in the model is as follows: runoff $Q_{t}$ (direct and indirect), evapotranspiration $\mathrm{ET}_{t}$, soil water storage $S_{t}$, and groundwater storage $G_{t}$. The partitioning is controlled by the magnitude of precipitation $P_{t}$, potential evapotranspiration $\mathrm{ET}_{0 t}$, and the initial storages in soil $S_{t-1}$ and groundwater $G_{t-1}$. The following equation controls the partitioning:

$Y_{t}\left(W_{t}\right)=\frac{W_{t}+b}{2 a}-\sqrt{\left(\frac{W_{t}+b}{2 a}\right)^{2}-\frac{W_{t} b}{a}}$,

where $Y_{t}$ is the sum of monthly evapotranspiration and soil water storage at the end of the month, namely evapotranspiration opportunity. $W_{t}$ is the sum of monthly precipitation and initial soil moisture, named as available water. The parameter $a(0 \sim 1)$ means the propensity in a catchment for runoff to occur before the soil becomes saturated. The parameter $b$ is the maximum value of $Y_{t}$. Wang and Tang (2014) demonstrated that Eq. (9) can be derived from the generalized proportionality hypothesis and is an equivalent Budykotype equation. Available water partitioning between $\mathrm{ET}_{t}$ and 

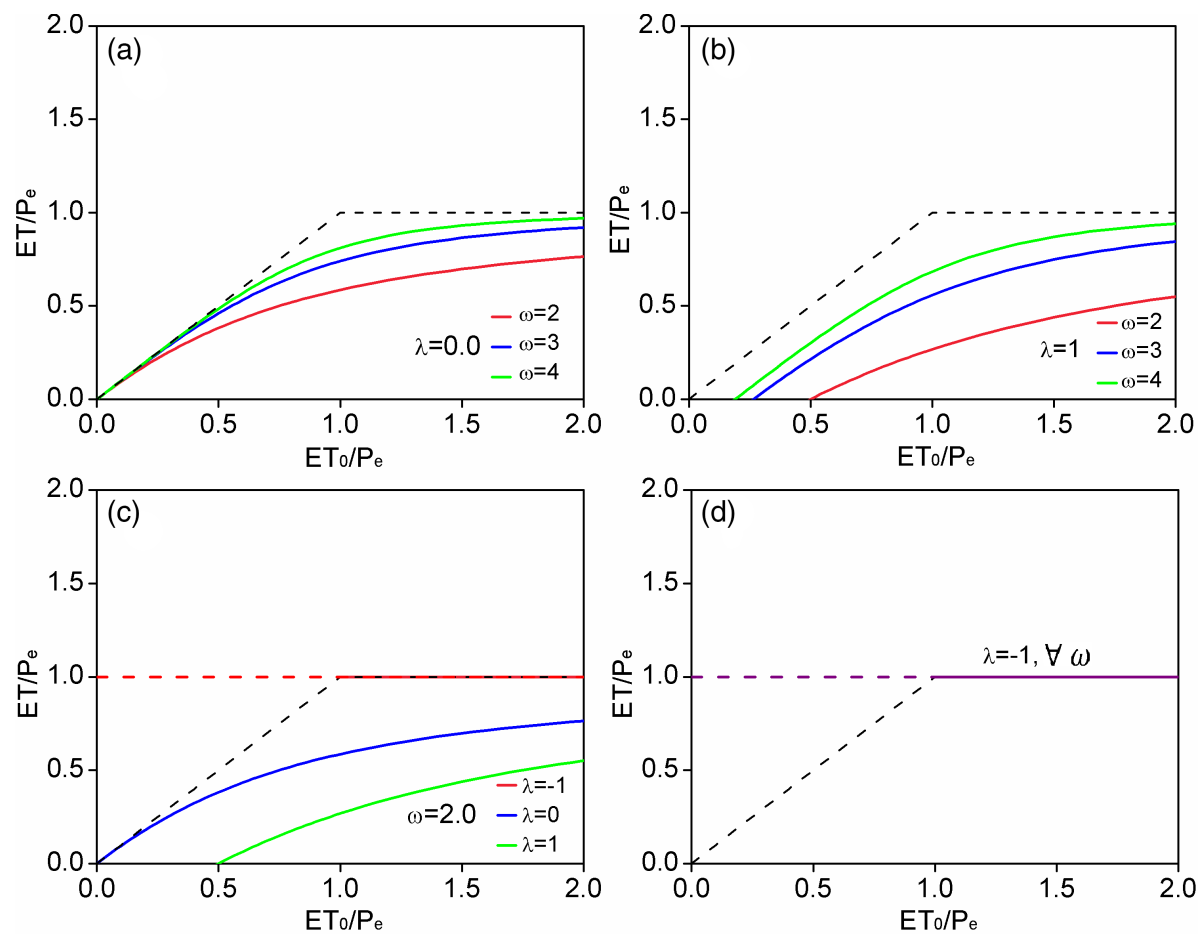

Figure 2. The Budyko curves in Eq. (8) with different combinations of parameters $\omega$ and $\lambda$.

$S_{t}$ is controlled by the assumption that the loss rate of actual evaporation from soil water storage is proportional to the evapotranspiration capacity. So the soil water storage at the end of period $t$ is written as

$S_{t}=Y_{t} \exp \left(-\mathrm{ET}_{0 \mathrm{t}} / b\right)$

The actual evapotranspiration at the period $t$ is the difference between evapotranspiration opportunity and soil water storage $\left(Y_{t}-S_{t}\right)$. The streamflow, including direct runoff and groundwater recharge, is determined by the difference between available water and evapotranspiration opportunity $\left(W_{t}-Y_{t}\right)$. The parameter $c$ separates the direct runoff $(1-$ $c)\left(W_{t}-Y_{t}\right)$ and groundwater recharge $c\left(W_{t}-Y_{t}\right)$. Groundwater discharge $\mathrm{dG}_{t}$ as the base flow is determined by the parameter $d$ and groundwater storage at the end of period $t$. The streamflow is sum of direct runoff and the base flow. For a given set of $a, b, c$ and $d$ and initial soil water storage and groundwater storage, the allocation of monthly precipitation can be computed one by one.

\section{Study area and data}

\subsection{Study area}

The HRB, originating from Qilian Mountains, is the second largest inland river basin in the arid area of the northwestern China (Fig. 3). The drainage map and the basin border are extracted using a $90 \mathrm{~m}$ resolution digital eleva- tion model (DEM) data from the Shuttle Radar Topography Mission (SRTM) website of NASA (http://srtm.csi.cgiar. org/SELECTION/inputCoord.asp) (basin length: $820 \mathrm{~km}$; total area: $143044 \mathrm{~km}^{2}$; elevation: $870-5545 \mathrm{~m}$ ). The HRB is in the middle of Eurasia and away from oceans, characterized with dry and windy climate, and very limited precipitation (mean annual precipitation: $126 \mathrm{~mm} \mathrm{yr}^{-1}$ ) but plentiful radiation (mean annual solar radiation: $1780 \mathrm{MJ} \mathrm{m}^{-2} \mathrm{yr}^{-1}$, $\sim 660 \mathrm{~mm} \mathrm{yr}^{-1}$ in the unit of evaporation).

The HRB is divided into six sub-basins according to basin characteristics, distributed along the eastern and western tributaries, shown in Fig. 3. Regions I and II are upper mountainous regions with the elevation of $3000-5500 \mathrm{~m}$ and belong to the cold and semiarid mountainous zone dominated by shrubs and trees with mean annual temperature of less than $2{ }^{\circ} \mathrm{C}$ and annual precipitation of $200-400 \mathrm{~mm}$. And these two sub-basins are the water source area to the middle and lower reaches and have little interference of human activities. Regions III and V with annual precipitation of 100-250 mm are the main irrigation zone and residential area with more than $90 \%$ of total population of the HRB. The two sub-basins are the main water-consuming regions and largely disturbed by human activities. Regions IV and VI located at lower reaches are extremely arid and the mean annual precipitation is less than $100 \mathrm{~mm}$. 


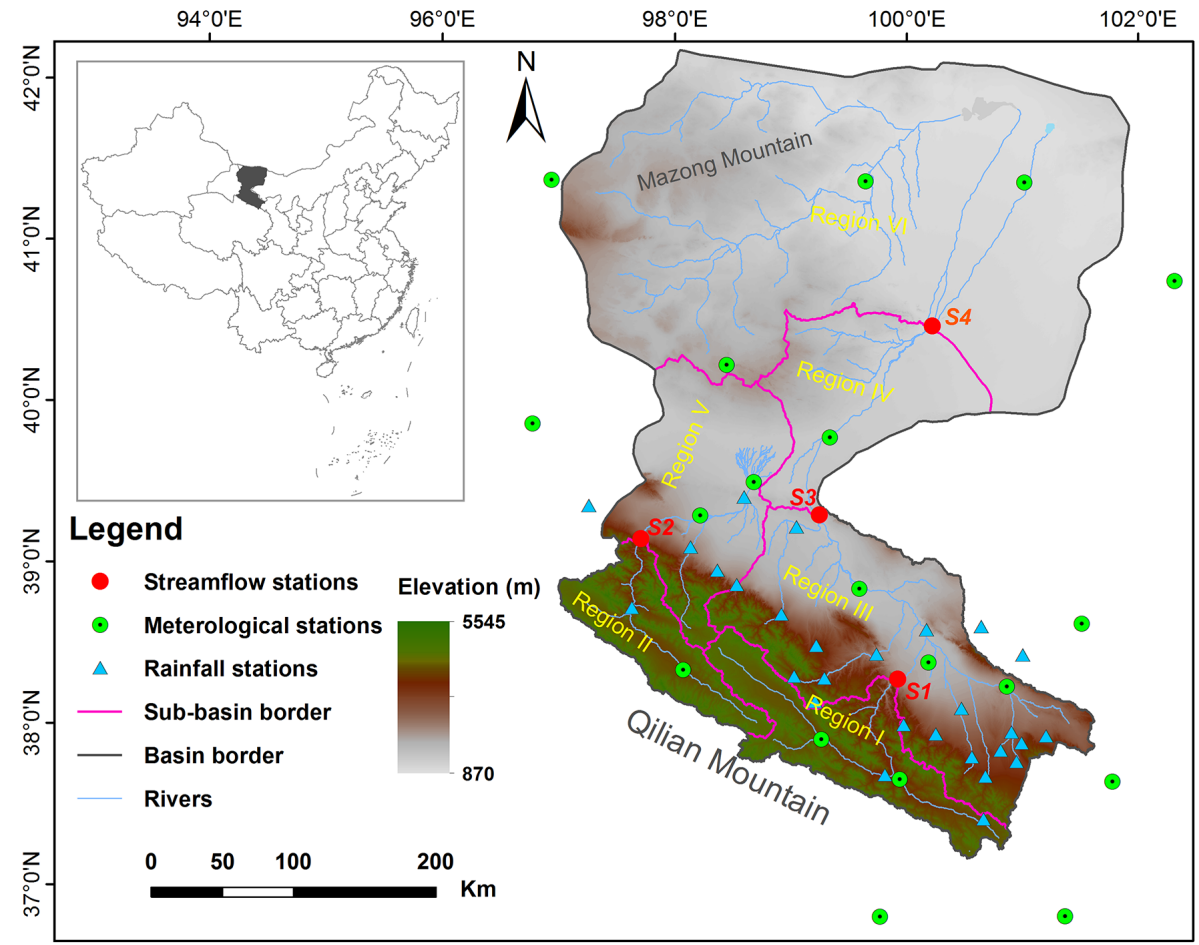

Figure 3. Location of study area and the distribution of hydrological stations and meteorological stations.
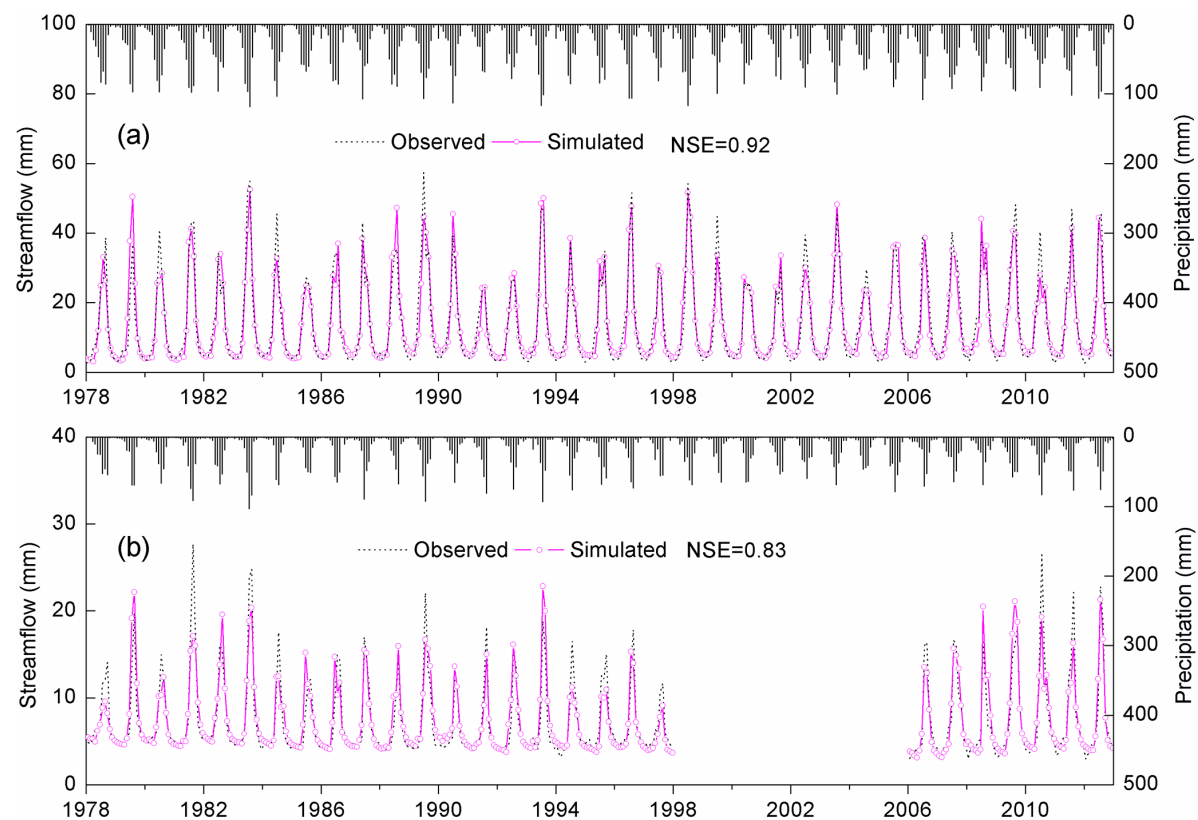

Figure 4. Time series of observed and simulated monthly streamflow using the $a b c d$ model in region I (a) and region II (b) during $1978-2012$.

\subsection{Data}

The required data for Eq. (8) and the abcd model include monthly precipitation, potential evapotranspiration and runoff from those sub-basins in the HRB.
The daily precipitation data of all stations during 19782012 are obtained from the year book hydrology of China including 28 rainfall stations and the China Administration of Meteorology including 19 meteorological stations (Fig. 3). The monthly precipitation of each station is calculated by 
summing daily precipitation. The gridded data set with $1 \mathrm{~km}$ resolution across the whole basin is obtained by interpolation of the site data. The monthly precipitation of the six subbasins is obtained by the extraction from the monthly precipitation in the whole basin. Daily meteorological data of 19 stations during 1978-2012 are also available. Daily potential evapotranspiration is estimated in each station using the FAO Penman-Monteith equation recommended by Allen et al. (1998). The monthly $\mathrm{ET}_{0}$ at each station is the sum of the daily $\mathrm{ET}_{0}$ and then interpolated to the whole basin. Finally, annual runoff, precipitation and potential evapotranspiration are obtained by summing monthly data.

The red points in Fig. 3 are the locations of hydrological stations. For the two upper streams, Gauge S1 controls region I and Gauge S2 controls region II. For the two middle streams, Gauges S1 and S3 control region III and Gauges S3 and S4 control region IV. For the two lower streams, regions $\mathrm{V}$ and VI without any runoff flowing out, Gauges S2 and S4 control their inflow, respectively (Fig. 3). Monthly runoff data are obtained from the year book of hydrology of China and are intended for calibrating the abcd model. The annual runoff is obtained by summing monthly runoff. The data time series for regions I and III are from 1978 to 2012. The same period is for regions II and V but with the period of 19982006 missing. The length of the data time series for regions IV and VI is from 1988 to 2012.

The natural runoff in regions III and IV were strongly disturbed by human activities and there is no runoff for regions $\mathrm{V}$ and VI and the whole basin. To validate the outputs of the abcd model for those regions, this study employs the evapotranspiration of remote sensing products from Heihe Plan Science Data Center (Wu et al., 2012) as a reference. The same data have been widely used as a reference for modeling evaluations and is supported by a State Key Research Program-Heihe Eco-hydrological Research Project of National Natural Science Foundation of China (Yan et al., 2014; Yao et al., 2014). The monthly evapotranspiration data sets (2000-2012) with $1 \mathrm{~km}$ spatial resolution over the HRB (http://westdc.westgis.ac.cn), are estimated by the ETWatch model based on multi-source remote sensing data (Wu et al., 2012).

\section{Results}

\subsection{Calibration of the abcd model}

In extremely dry basins like the HRB, the lack of observed hydro-climatic data presents great challenge. A monthly water balance model becomes an effective tool to estimate actual evapotranspiration, change in soil water storage and change in groundwater storage. This study employs the abcd water balance model due to its simple and sound physical structure tested and recommended by Alley (1984) and Fernandez et al. (2000). We calibrate and validate the $a b c d$
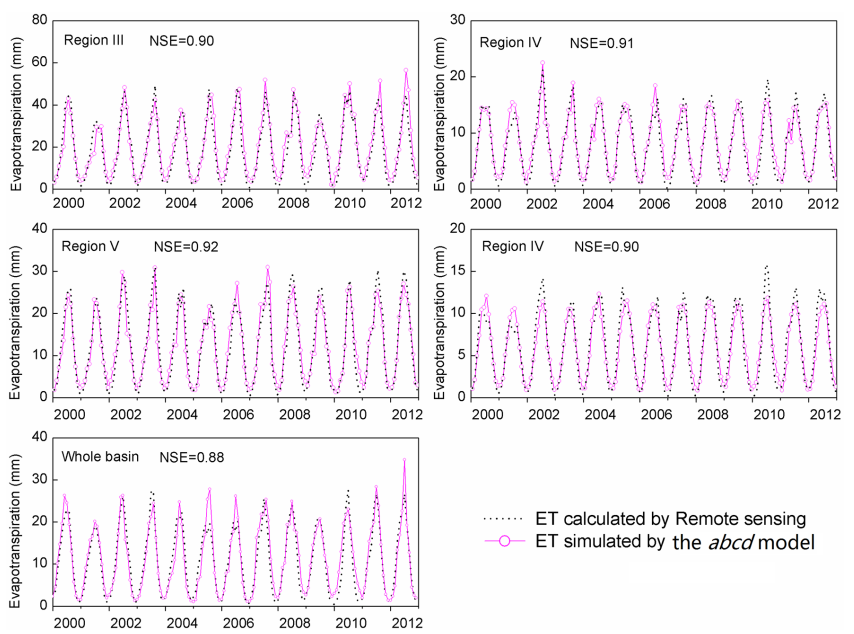

ET calculated by Remote sensing - ET simulated by the abcd model

Figure 5. Comparison between ET simulated by the abcd model and ET calculated by remote sensing data for regions III-VI and the whole basin during 2000-2012. "WBM" denotes the abcd water balance model.

model using monthly time series of precipitation, potential evapotranspiration and runoff at each of the seven regions (the six sub-basins and the whole basin) and using the generalized pattern search optimization method. Nash-Sutcliffe efficiency (NSE) is used to assess the goodness of fit of the monthly water balance for the seven regions.

Figure 4 shows the results of the modeled streamflow at monthly timescales in regions I and II. Regions I and II are the water source area of the whole basin with little interference of human activities and both keep relatively natural steady state. The NSE for regions I and II is for 0.92 and 0.83 , respectively. The results illustrate that the simulated monthly streamflow agrees well with the observation and other modeled components can be reasonable estimates, for instance, monthly actual evapotranspiration, soil water storage change and groundwater storage change in the two sub-basins.

The outputs from the $a b c d$ model being used include soil water storage and actual evapotranspiration. Only over the two upper sub-basins (regions I and II) is the streamflow used for the calibration and validation purpose.

Over the middle sub-basins (regions III, IV and also V), large areas of artificial oasis (cropland) is distributed and the streamflow water intensely disturbed by hydraulic engineering. Hence it becomes almost impossible to validate the abcd model by directly comparing the simulated and observed streamflow. Instead, we used the actual evapotranspiration by remote sensing to calibrate and validate the $a b c d$ model. For the new BH over regions III, IV and V, we use the observed $Q_{\text {in }}$ from the upper sub-basin as the input. That is to be consistent with the remote sensing data, which are observed and hence human disturbed. 
Table 2. The mean annual water balance of all regions.

\begin{tabular}{lllllll}
\hline Region & $P(\mathrm{~mm})$ & $Q_{\text {in }}(\mathrm{mm})$ & ET $(\mathrm{mm})$ & $Q_{\text {out }}(\mathrm{mm})$ & $\Delta S(\mathrm{~mm})$ & PWS $(\%)$ \\
\hline I & 351.9 & - & 165.3 & 169.3 & 0.0 & 0.0 \\
II & 220.7 & - & 143.9 & 85.2 & 0.1 & 0.0 \\
III & 223.6 & 66.1 & 253.2 & 37.5 & -2.1 & -0.9 \\
IV & 73.5 & 74.0 & 103.4 & 47.5 & 1.0 & 1.3 \\
V & 117.3 & 39.6 & 156.7 & - & 0.2 & 0.1 \\
VI & 66.8 & 7.9 & 74.7 & - & 0.0 & 0.0 \\
Whole basin & 125.8 & - & 125.5 & - & 0.2 & 0.2 \\
\hline
\end{tabular}

“-” means no runoff; PWS represents the proportion of the root zone water storage change in the total precipitation.
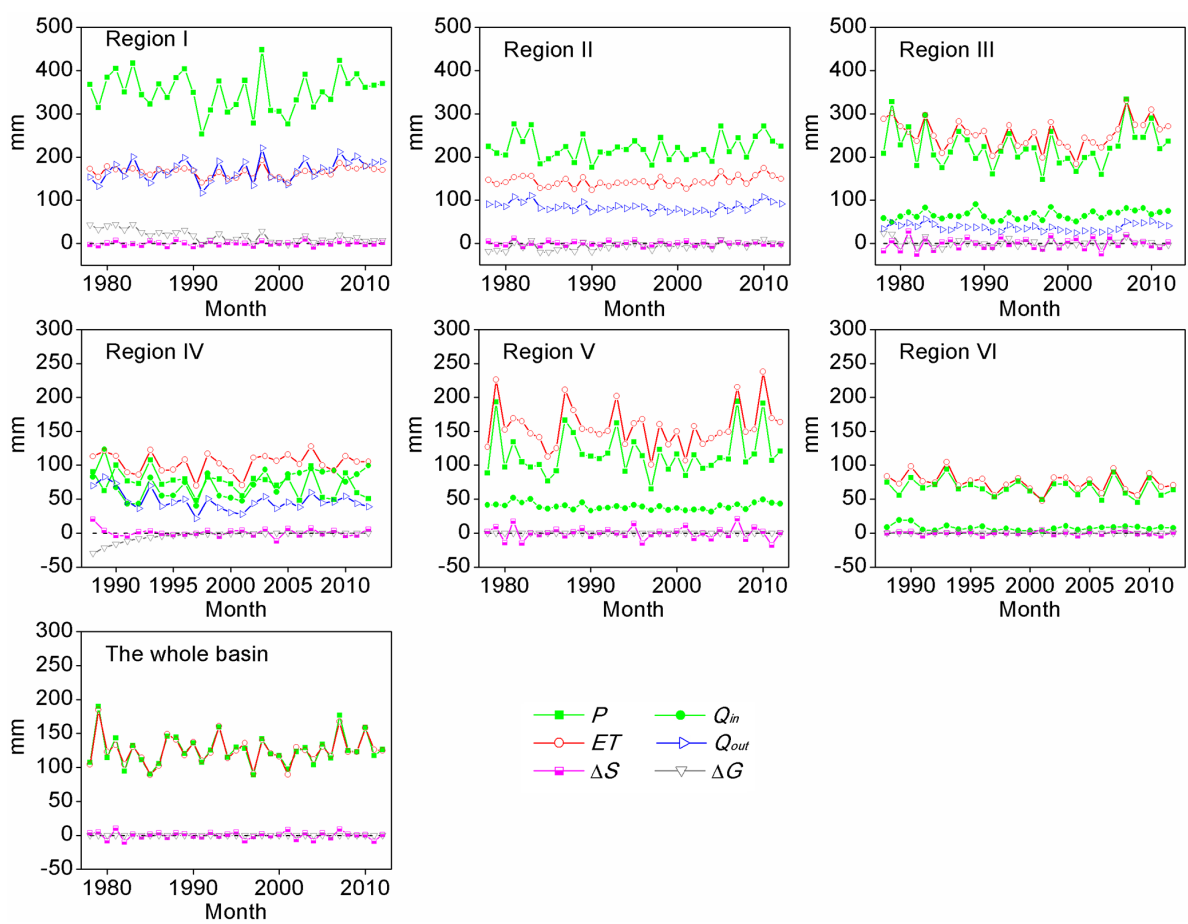

Figure 6. Variation of annual water balance for all the regions simulated using the $a b c d$ model.

\subsection{Annual and monthly water balance analysis}

To test the "steady-state" assumption of the Budyko framework, it is vital to examine whether changes in mean annual soil water storage in water balance approach zero. By using the monthly runoff, evapotranspiration, soil water and groundwater storage change from the abcd model and the observed monthly precipitation, the mean annual water balance of all regions are summarized in the Table 2. Regions I and II are located in mountainous area, where the mean annual soil water storage changes are almost zero with both $0.0 \%$ of the corresponding precipitation. The mean annual soil water storage change in regions III and IV are relatively significant. For regions V and VI and the whole basin without any outflow, the mean annual soil water storage and groundwater storage changes both approach zero. In conclusion, the mean annual soil water storage changes for all regions are very small and can be ignored in mean annual water balance. These sub-basins and the whole basin keep natural basin characteristics and meet the second assumption of the $\mathrm{BH}$ that mean annual soil water storage can be ignored. However, no inflow only exists in regions I and II, which meets the first assumption of the $\mathrm{BH}$ that the local precipitation is the only potential water source to evapotranspiration. In other regions, water supply conditions have been changed by considerable inflow generally from upper sub-basins.

Because this study focuses on the application of the $\mathrm{BH}$ at the annual and monthly timescales, the annual and monthly water balance analysis is very critical to understanding the role of water storage and water source change in the $\mathrm{BH}$. Figure 6 describes the variation of annual water balance for the six sub-basins and the whole basin. The most obvious in 

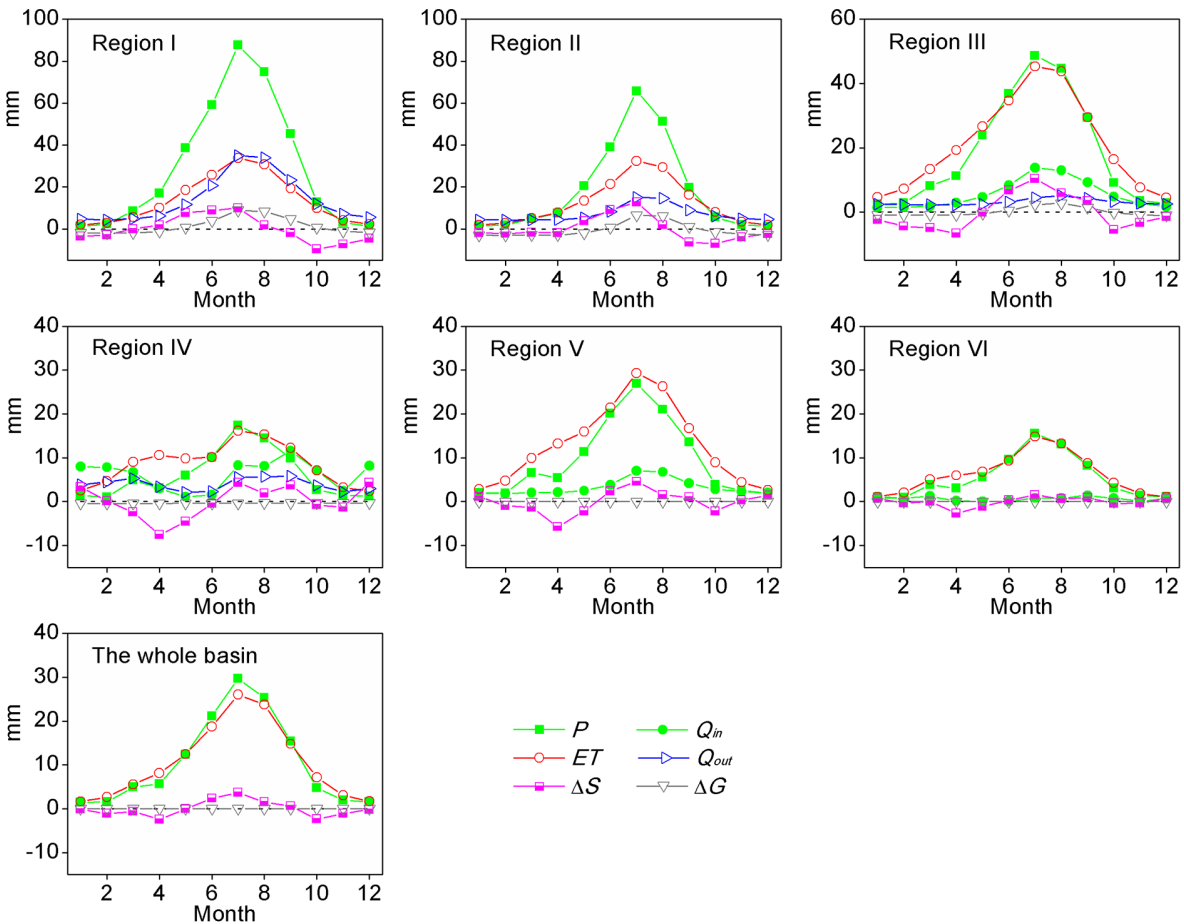

$$
\begin{array}{ll}
\longrightarrow P & \longrightarrow Q_{\text {in }} \\
\multimap-E T & \longrightarrow Q_{\text {out }}
\end{array}
$$

Figure 7. Variation of average monthly water balance for all regions using the $a b c d$ model.

Table 3. The fitting parameters of Fu's equation at annual scales.

\begin{tabular}{llllllll}
\hline Region & I & II & III & IV & V & VI & Whole basin \\
\hline$\omega^{*}$ & 1.34 & 1.45 & 2.05 & 1.42 & 20.28 & 13.05 & 17.60 \\
$\omega^{* *}$ & 1.45 & 1.69 & 2.34 & 1.44 & 1.07 & 10.8 & 1.09 \\
$\lambda^{* *}$ & 0.25 & 0.67 & 0.62 & 0.08 & -1 & -1 & -1 \\
\hline
\end{tabular}

* means the calibrated values of $\omega$ in Fu's equation; Eq. (8) when $\lambda=0$;

*** means the calibrated values of $\omega$ and $\lambda$ in Eq. (8).

Fig. 6 is that the proportion of soil water storage change in annual water balance is small compared with the annual precipitation. So the impact of soil water storage change on annual water balance is insignificant and can be also neglected. Moreover, annual evapotranspiration is higher than annual precipitation in regions III-VI and approaches annual precipitation over the whole basin. For water-limited regions, when inflow from other regions is available, the actual evapotranspiration increases with the increased water supply so that the actual evapotranspiration is more than the local precipitation. For the whole basin of the inland HRB, there is no water transferring with other basins, so the evapotranspiration almost approaches the precipitation at the annual timescale due to little variations in the soil water storage changes. In conclusion, the facts that soil water storage change in all basins can be ignored in annual water balance meet the second assumption of the $\mathrm{BH}$, and the results that the annual water balance in regions III-VI and the whole basin have been disturbed do not meet the first assumption of the $\mathrm{BH}$. Therefore, except for regions I and II, the original $\mathrm{BH}$ cannot be directly used for those sub-basins and the whole basin.

Different from the annual timescale, the impacts of monthly changes of soil water storage and groundwater storage behave differently (Fig. 7). The variations of monthly groundwater storage change for all regions are similar to those of runoff (Fig. 7). For those regions with no runoff (regions V and VI and the whole basin), the modeled groundwater storage change is almost zero. This means that the groundwater storage can hardly contribute to the evapotranspiration while the variation of soil water storage is tightly coupled with the evapotranspiration (Fig. 7). For regions I and II and during the winter season, the evapotranspiration is more than the precipitation; the extra water source required by the evapotranspiration is from root zone water storage. After the summer season, the precipitation sharply decreases, but the evapotranspiration slowly decreases by consuming the root zone water storage recharged during the summer season. For regions III-VI, the water supply is more complicated 

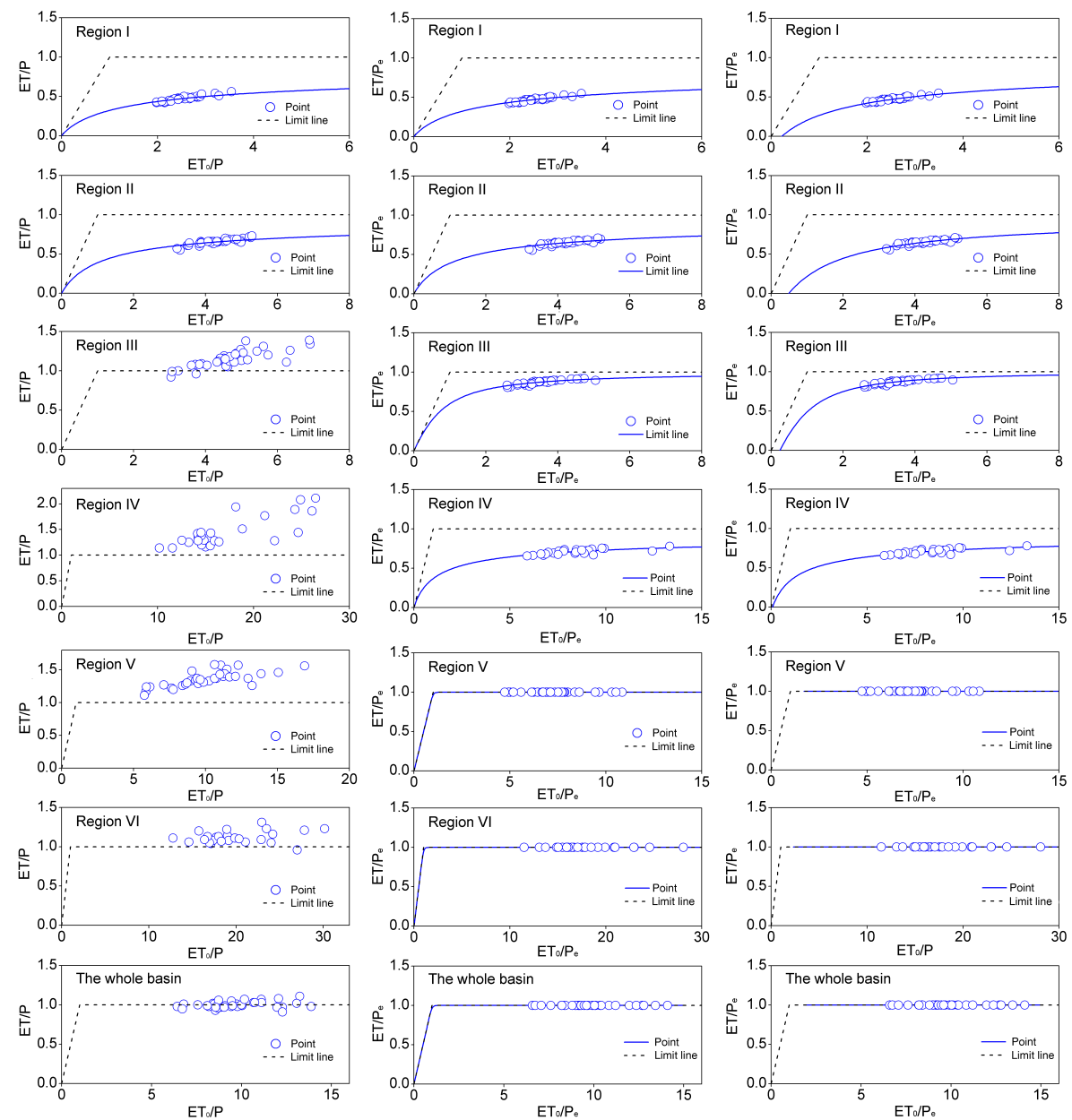

Figure 8. Comparison of the original Budyko curves (left panel) and the new Fu-type Budyko curves (middle panel, with $\lambda=0$ ) and the new Fu-type Budyko curves (right panel, with $\lambda>0$ ) for regions I-VI and the whole basin at the annual timescale.

by the interference of monthly inflow water, and the monthly variations of root zone water storage. As shown in Fig. 7, it can be concluded that both the soil water storage change and inflow water have obvious effect on the monthly water balance, whilst the impact of monthly groundwater storage change is negligible.

In summary, due to the complications of the water transfer and soil water storage change, the two assumption conditions for applying the original $\mathrm{BH}$ are difficult to meet for the subbasins and the whole HRB on the monthly timescales, which in turn requires new treatments in the $\mathrm{BH}$ as further investigated in the following sections.

\subsection{The annual Budyko curve analysis}

Figure 8 (left panel) plots the original Budyko curves for the six sub-basins and the whole basin. For regions I and II, the points of annual evapotranspiration ratio and aridity index fall in the domain of water and energy limit boundary and they can be well fitted by Fu's equation. The relationship be- tween water and energy in regions I and II can be described by the original $\mathrm{BH}$ as expected in the section above. However, the points of evapotranspiration ratio and aridity index for other regions exceed the water limit boundary. And the results show the relationship of water and energy in regions III-VI, and the whole basin is inconsistent with the original $\mathrm{BH}$. After using the equivalent precipitation instead of the local precipitation, the new Fu-type Budyko curves (Eq. (8) with $\lambda=0$ ) for all regions are shown in Fig. 8 (middle panel). Compared with the original Budyko curve, the new curves for regions I and II did not behave differently, because the two basins are natural and closed. The obvious change between the improved and original Budyko curves are for regions III and IV. For the whole basin and regions V and VI, the new curves fall on the upper limit of ET / $P_{\mathrm{e}}=1$ due to no runoff flowing out. These improved Budyko curves can be fitted using Fu's equation and the parameters are listed in Table 3. Interestingly for the annual timescale, the fitted performances of Fu's equation and Eq. (8) are almost identical. Therefore, the new Fu-type Budyko curves (Eq. 8) with fitted 
Table 4. The fitting parameters of the improved Budyko equation at the monthly scales.

\begin{tabular}{|c|c|c|c|c|c|c|}
\hline Region & Parameter & May-Aug & Apr and Sep & Mar and Oct & Feb and Nov & Jan and Dec \\
\hline \multirow{3}{*}{ I } & $\omega^{*}$ & 1.40 & 1.39 & 1.35 & 1.28 & 1.22 \\
\hline & $\omega^{* *}$ & 1.50 & 1.51 & 1.48 & 1.40 & 1.33 \\
\hline & $\lambda^{* *}$ & 0.16 & 0.24 & 0.31 & 0.32 & 0.28 \\
\hline \multirow{3}{*}{ II } & $\omega^{*}$ & 1.54 & 1.53 & 1.47 & 1.37 & 1.29 \\
\hline & $\omega^{* *}$ & 1.70 & 1.72 & 1.67 & 1.57 & 1.48 \\
\hline & $\lambda^{* *}$ & 0.34 & 0.54 & 0.63 & 0.66 & 0.60 \\
\hline Region & Parameter & Apr-Sep & Mar and Oct & Feb and Nov & Jan and Dec & \\
\hline \multirow{3}{*}{ III } & $\omega^{*}$ & 2.20 & 2.05 & 1.86 & 1.71 & \\
\hline & $\omega^{* *}$ & 2.31 & 2.15 & 1.97 & 1.90 & \\
\hline & $\lambda^{* *}$ & 0.18 & 0.19 & 0.22 & 0.39 & \\
\hline \multirow{3}{*}{ IV } & $\omega^{*}$ & 1.51 & 1.42 & 1.33 & 1.25 & \\
\hline & $\omega^{* *}$ & 1.75 & 1.59 & 1.51 & 1.41 & \\
\hline & $\lambda^{* *}$ & 0.92 & 0.53 & 0.56 & 0.41 & \\
\hline Region & Parameter & May-Aug & Apr and Sep & Mar and Oct & Feb and Nov & Jan and Dec \\
\hline \multirow{3}{*}{ V } & $\omega^{*}$ & 35.5 & 29.8 & 28.0 & 22.5 & 23.7 \\
\hline & $\omega^{* *}$ & 1.02 & 1.03 & 1.03 & 1.04 & 1.04 \\
\hline & $\lambda^{* *}$ & -1 & -1 & -1 & -1 & -1 \\
\hline \multirow{3}{*}{ VI } & $\omega^{*}$ & 17.3 & 18.9 & 15.5 & 12.7 & 13.1 \\
\hline & $\omega^{* *}$ & 1.02 & 1.02 & 1.03 & 1.03 & 1.04 \\
\hline & $\lambda^{* *}$ & -1 & -1 & -1 & -1 & -1 \\
\hline \multirow{3}{*}{ The whole basin } & $\omega^{*}$ & 28.5 & 22.4 & 18.8 & 16.3 & 15.7 \\
\hline & $\omega^{* *}$ & 1.02 & 1.02 & 1.04 & 1.04 & 1.03 \\
\hline & $\lambda^{* *}$ & -1 & -1 & -1 & -1 & -1 \\
\hline
\end{tabular}

* Means the calibrated values of $\omega$ in Fu's equation; Eq. (8) when $\lambda=0$;

** means the calibrated values of $\omega$ and $\lambda$ in Eq. (8).

values of $\lambda$ (right panel, Fig. 8) do not show much difference from those curves with $\lambda$ set zero.

In summary, if a basin (sub-basin) is closed, the original $\mathrm{BH}$ can be applicable at the annual timescale. However under unsteady state, the new Fu-type $\mathrm{BH}$, instead of the original $\mathrm{BH}$, is more applicable to describe the annual water balance.

\subsection{The monthly Budyko curves analysis}

Again as expected based on the monthly water balance analysis, the points of monthly evapotranspiration ratio and aridity index exceed the water limit boundary for all the basins (Fig. 9, left panel). The value of evapotranspiration ratio can be up to 40, which means that the local precipitation in original water balance is well below the actual water supply to the evapotranspiration. The new Fu-type Budyko curves at the monthly timescale are shown in Fig. 9 in the middle panel (Eq. 8 with setting $\lambda=0$ ) and in the right panel (Eq. 8 with calibrated $\lambda$ ). It is remarkable that the points of monthly evapotranspiration ratio and aridity index distribute regularly in the Budyko framework (in Fig. 9, middle panel and right panel). The improved Budyko curves with calibrated $\lambda$ perform better than Fu's original equation (i.e., $\lambda=0$ ) by 5 $10 \%$ in terms of NSE. The fitting parameter $\lambda$ introduced in this study (Eq. 8) can add further improvement to the BH, in spite of obviously deserving further investigations.

The fitted values of the parameters in the Budyko curves for regions I to VI are listed in the Table 4. These curves and the parameters have significantly seasonal characteristics. For example, the Budyko curves in regions I and II can be divided to five groups (Fig. 9). The values of the integrated parameter $\omega$ in Eq. (8) gradually decrease from the summer months to winter months. The absolute values of parameters $\lambda$ gradually increase, which illustrates that the points in summer months are more centralized than those in winter months. Moreover, in regions V and VI and the whole basin, all the equivalent precipitation is consumed by evapo- 

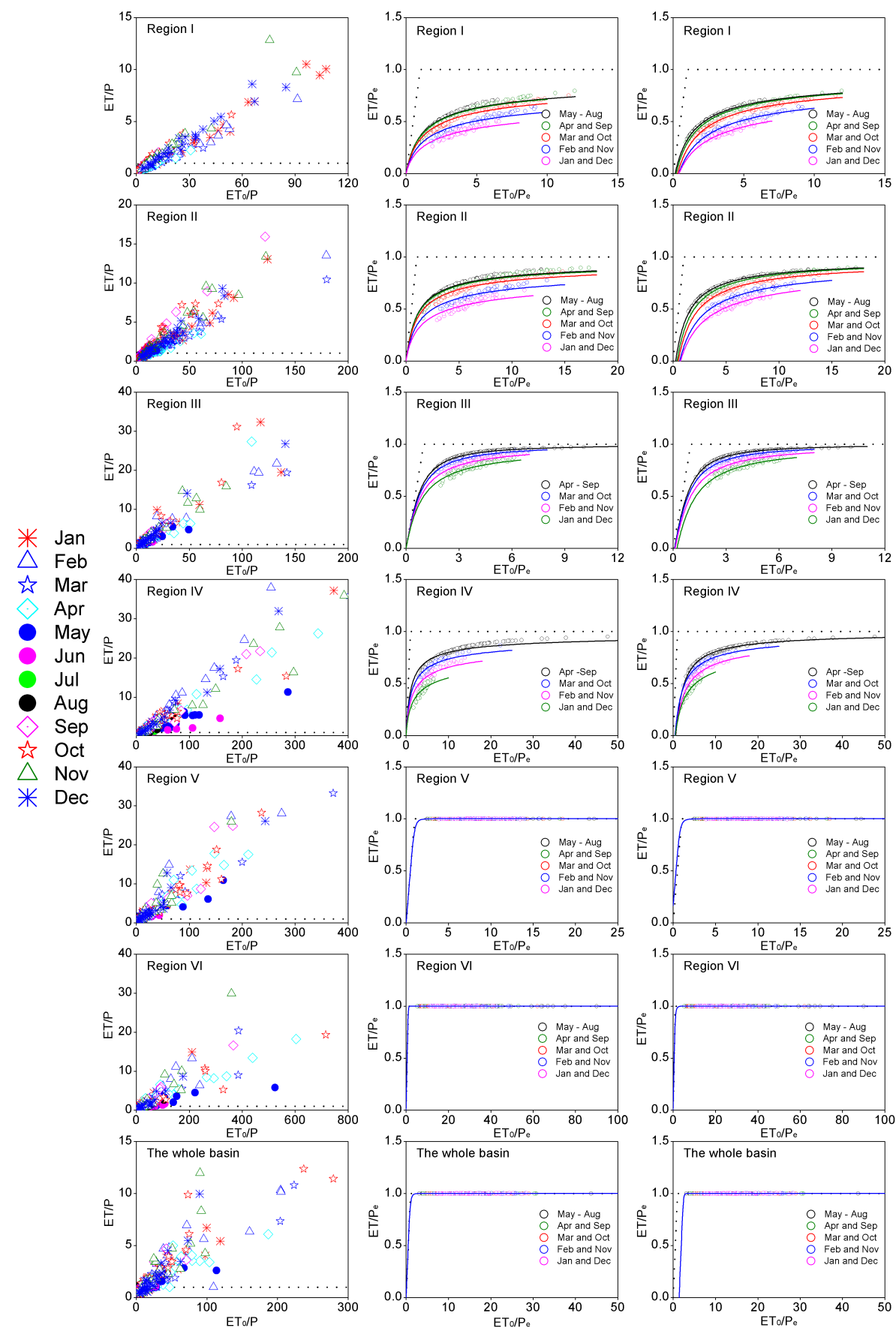

Figure 9. Comparison of the original Budyko curves (left panel) and the new Fu-type Budyko curves (middle panel, with $\lambda=0$ ) and the new Fu-type Budyko curves (right panel, with $\lambda>0$ ) for regions I-VI and the whole basin at the monthly timescale.

transpiration, and therefore the ratio of evapotranspiration to the equivalent precipitation is almost 1 .

\subsection{Storage change and inflow water impact on the BH}

In this study, we intended to extend the $\mathrm{BH}$ to the annual and sub-annual time scales by explicitly considering the root zone water storage and new water source from other regions.
To further investigate it, we choose regions I and III as typical cases in Fig. 10. In region I, as there is no inflow into the region, we can separate the impact of soil water storage and groundwater storage on the BH (Fig. 10a). With subtle differences, the impacts of changes in root zone water storage and groundwater storage on water balance can be almost ignored at annual scales. Region III is another extreme case 

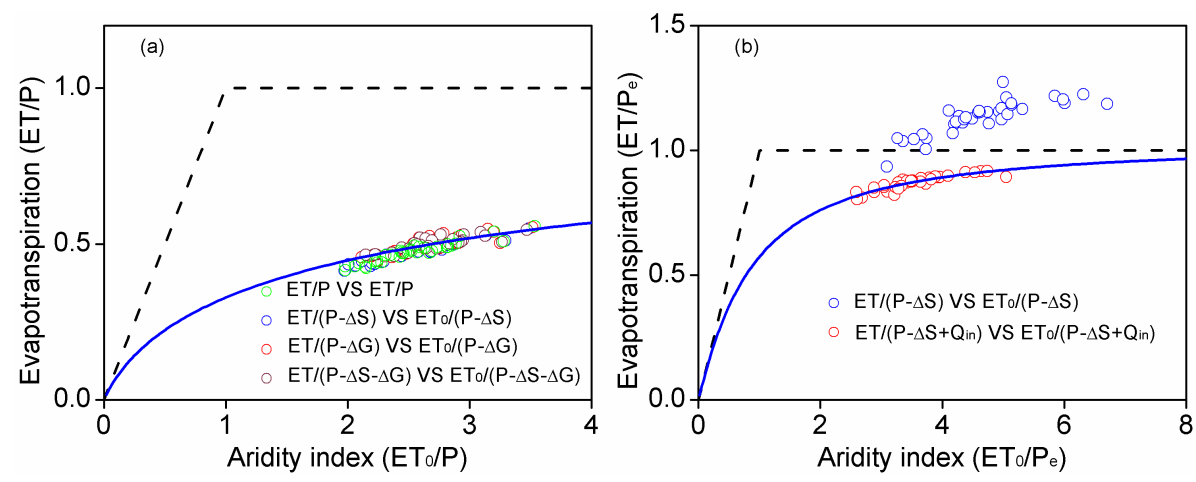

Figure 10. Different presentations of the annual water balance for (a) region I and (b) region III.
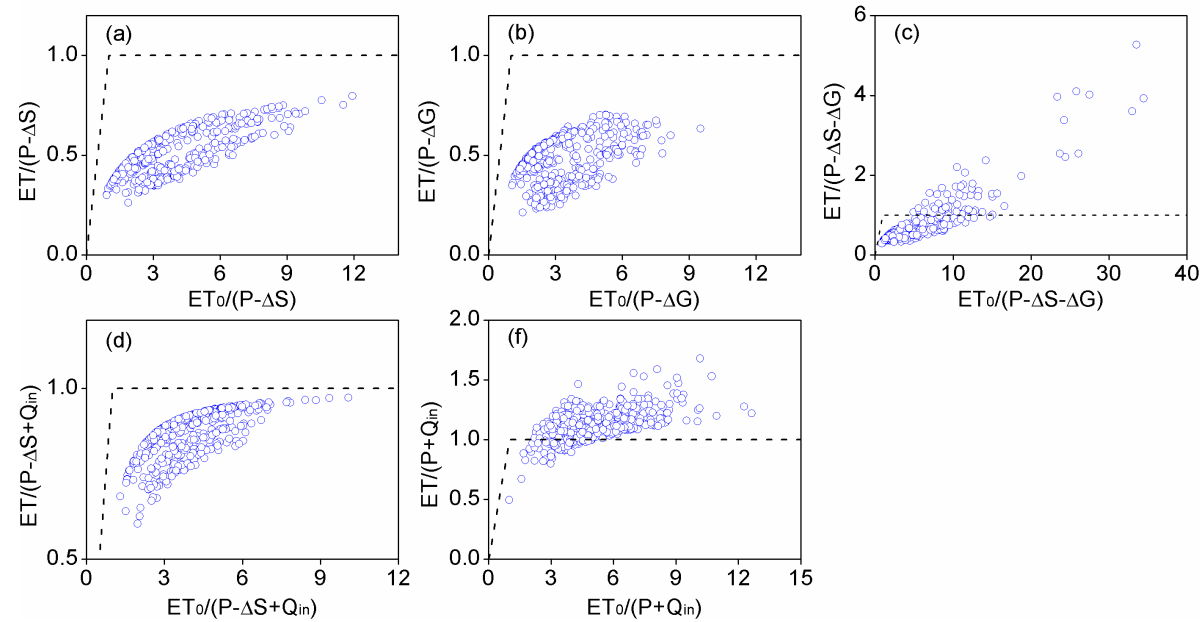

Figure 11. Five presentations of monthly water balance for region III considering different combinations in the water supply to evapotranspiration.

where only if the role of the inflow water is considered, can the BH perform well under unsteady state (Fig. 10b).

In Fig. 11, we further adopted the approach presented by Chen et al. (2013) to examine the impacts of soil water storage, groundwater storage and inflow water on monthly water balance. We test different combinations in monthly water balance in region III, a midstream sub-basin of the HRB (Fig. 11a-c), and found that when the equivalent precipitation includes the root zone water storage change the BH performs well at the monthly scale. However, the inclusion of the groundwater storage change into the equivalent precipitation does not improve as much (Fig. 11b, c). By examining the impact of monthly inflow water on the BH in region III (Fig. 11d, f), we find that inflow water at the monthly scale has as much impact as that at annual scale. The results presented above highlight the fact that the water supply cannot be the local precipitation only, but should have included root zone water storage change and inflow water.

\section{Conclusions}

The Budyko hypothesis (BH) is a useful approach to depicting and understanding the long-term mean water balance at a large basin scale under a steady-state condition. However, river systems worldwide have in fact been disturbed by human activities to different extents. That is important for extremely arid environments (say, the aridity index over 5 ), especially in China, where water systems are typically unclosed with intense human inference and irrigation. That presents a great challenge if one is applying the $\mathrm{BH}$ to those regions under unsteady state, e.g., unclosed or significant variation in soil water storage, or those timescales finer than a year.

To investigate it, we choose an extremely arid inland basin, the Heihe River basin in China, as the study area, which is divided into six sub-basins based on catchment hydrologic characteristics. We first calibrate and validate a widely used monthly water balance model, i.e., the abcd model. For the two upper sub-basins, the simulated monthly water balance is compared against monthly streamflow from 
hydrological gauges, and for the other sub-basins and the whole catchment, the simulated evapotranspiration is compared with widely used remote sensing ET products in the HRB. The abcd model can successfully simulate the monthly water balance and capture the inter-annual variations (NSE over 0.85 ). Based on that, we find that the role of root zone water storage change in monthly water balance is significant but almost negligible over timescales longer than a year. And the impact of inflow water from upper sub-basins is also significant and does not rely on the timescale. We conclude that the upstream basins in the HRB are almost closed basins, which meet the two steady-state conditions of the $\mathrm{BH}$, and other sub-basins become an unclosed basin due to the impact of the inflow water and human interference.

With the recognition that the inflow water from other regions and the water storage change are both new possible water sources to evapotranspiration in unclosed basins, we define the equivalent precipitation $\left(P_{\mathrm{e}}\right)$ including the local precipitation, inflow water and water storage change as the water supply, instead of just the local precipitation, in the Budyko framework. (The evapotranspiration ratio and the aridity index are also redefined using the equivalent precipitation.) In addition to the new definition of the water supply, we develop a new Fu-type Budyko equation with two non-dimensional parameters $(\omega$ and $\lambda)$ based on the deviation by Professor Baopu Fu, i.e., Fu's equation, to consider the effect of the change of root zone water storage and the inflow water on the water and energy constraints. Over the annual timescale, the new Fu-type Budyko equation developed here has a more or less identical performance to Fu's equation for the subbasins and the whole catchment. However, for the monthly timescale, the new Fu-type Budyko equation performs better than Fu's original equation when the ratio of evapotranspiration to equivalent precipitation less than 1 , and performs the same when the evapotranspiration ratio is very close to 1 . The new Fu-type Budyko equation ( $\omega$ and $\lambda$ ) developed in this study enables one to apply the BH to interpret regional water balance over extremely dry environments under unsteady state (e.g., unclosed basins or sub-annual timescales). 
Appendix A: Derivation of the constraints of $\lambda$ in new Fu-type Budyko equation

For an unclosed basin or region, the water supply to evapotranspiration is defined as equivalent precipitation $\left(P_{\mathrm{e}}=\right.$ $\left.P+Q_{\text {in }}-\Delta S\right)$. Evapotranspiration ratio: $\varepsilon=\mathrm{ET} / P_{\mathrm{e}}$ and aridity index: $\phi=\mathrm{ET}_{0} / P_{\mathrm{e}}$. The Budyko equation is written the same as Eq. (8).

$\varepsilon=1+\phi-\left(1+\phi^{\omega}+\lambda\right)^{1 / \omega}$

According to the constrained boundary of the BH, (1) the evapotranspiration ratio is less than or equal to the aridity index, namely $\varepsilon \leq \phi$, and (2) the evapotranspiration ratio is no more than 1 ; i.e., $\varepsilon \leq 1$.
With $\varepsilon \leq \phi$, we can have

$$
1+\phi-\left(1+\phi^{\omega}+\lambda\right)^{1 / \omega} \leq \phi .
$$

Therefore,

$\phi^{\omega}+\lambda \geq 0$

where $\phi \geq 0$ and $\omega>1$.

For the other constraint, $\varepsilon \leq 1$ we can derive

$1+\lambda \geq 0$ 
Acknowledgements. This research was supported by the National Natural Science Foundation of China (41271049), the Chinese Academy of Sciences (CAS) Pioneer Hundred Talents Program, and an open research fund for the State Key Laboratory of Desert and Oasis Ecology, Xinjiang, Institute of Ecology and Geography, Chinese Academy of Sciences. The authors would like to thank Hubert H. G. Savenige and Wang Ping for their suggestions and support in this research. We are particularly grateful to the two reviewers Wang Dingbao and Gao Hongkai for their efforts and helpful comments.

Edited by: H. Li

\section{References}

Allen, R. G., Pereira, L. S., Raes, D., and Smith, M.: Crop evapotranspiration - Guidelines for computing crop water requirements, FAO Irrigation and drainage paper 56, 24, 55-56, 1998.

Alley, W. M.: On the Treatment of Evapotranspiration, Soil Moisture Accounting, and Aquifer Recharge in Monthly Water Balance Models, Water Resour. Res., 20, 1137-1149, doi:10.1029/WR020i008p01137, 1984.

Bonacci, O. and Andric, I.: Impact of an inter-basin water transfer and reservoir operation on a karst open streamflow hydrological regime: an example from the Dinaric karst (Croatia), Hydrol. Process., 24, 3852-3863, doi:10.1002/hyp.7817, 2010.

Budyko, M. I.: Evaporation Under Natural Conditions, Gedrometeoizdat, St. Petersburg, Russia, 29 pp., 1948.

Budyko, M. I.: The Heat Balance of the Earth's Surface, Department of Commerce, Weather Bureau, 144-155, 1958.

Budyko, M. I.: Climate and Life: Volume 18 International geophysics series, Academic Press, 1-508, 1974.

Carmona, A. M., Sivapalan, M., Yaeger, M. A., and Poveda, G.: Regional patterns of interannual variability of catchment water balances across the continental US: A Budyko framework, Water Resour Res, 50, 9177-9193, doi:10.1002/2014wr016013, 2014.

Chen, X., Alimohammadi, N., and Wang, D.: Modeling interannual variability of seasonal evaporation and storage change based on the extended Budyko framework, Water Resour. Res., 49, 60676078, doi:10.1002/wrcr.20493, 2013.

Choudhury, B. J.: Evaluation of an empirical equation for annual evaporation using field observations and results from a biophysical model, J. Hydrol., 216, 99-110, doi:10.1016/s00221694(98)00293-5, 1999.

Donohue, R. J., Roderick, M. L., and McVicar, T. R.: Assessing the differences in sensitivities of runoff to changes in climatic conditions across a large basin, J. Hydrol., 406, 234-244, doi:10.1016/j.jhydrol.2011.07.003, 2011.

Fernandez, W., Vogel, R. M., and Sankarasubramanian, A.: Regional calibration of a watershed model, Hydrol. Sci. J., 45, 689707, doi:10.1080/02626660009492371, 2000.

$\mathrm{Fu}$, B. P.: On the Calculation of the Evaporation from Land Surface, Sci. Atmos. Sin., 5, 23-31, 1981.

Gao, H., Hrachowitz, M., Schymanski, S. J., Fenicia, F., Sriwongsitanon, N., and Savenije, H. H. G.: Climate controls how ecosystems size the root zone storage capacity at catchment scale, Geophys. Res. Lett., 41, 7916-7923, doi:10.1002/2014GL061668, 2014.
Gentine, P., D’Odorico, P., Lintner, B. R., Sivandran, G., and Salvucci, G.: Interdependence of climate, soil, and vegetation as constrained by the Budyko curve, Geophys. Res. Lett., 39, L19404, doi:10.1029/2012g1053492, 2012.

Gerrits, A. M. J., Savenije, H. H. G., Veling, E. J. M., and Pfister, L.: Analytical derivation of the Budyko curve based on rainfall characteristics and a simple evaporation model, Water Resour Res, 45, W04403, doi:10.1029/2008wr007308, 2009.

Gordon, L. J., Steffen, W., Jonsson, B. F., Folke, C., Falkenmark, M., and Johannessen, A.: Human modification of global water vapor flows from the land surface, P. Natl. Acad. Sci. USA, 102, 7612-7617, doi:10.1073/pnas.0500208102, 2005.

Istanbulluoglu, E., Wang, T., Wright, O. M., and Lenters, J. D.: Interpretation of hydrologic trends from a water balance perspective: The role of groundwater storage in the Budyko hypothesis, Water Resour. Res., 48, W00H16, doi:10.1029/2010wr010100, 2012.

Li, H.-Y., Sivapalan, M., Tian, F., and Harman, C.: Functional approach to exploring climatic and landscape controls of runoff generation: 1. Behavioral constraints on runoff volume, Water Resour. Res., 50, 9300-9322, doi:10.1002/2014WR016307, 2014.

Li, J., Tan, S., Chen, F., and Feng, P.: Quantitatively analyze the impact of land use/land cover change on annual runoff decrease, Nat. Hazards, 74, 1191-1207, doi:10.1007/s11069-014-1237-x, 2014.

Mezentsev, V. S.: More on the calculation of average total evaporation, Meteorol. Gidrol., 5, 24-26, 1955.

Milly, P. C. D.: An Analytic Solution of The stochatic Storage Problem Applicable to Soil Water, Water Resour. Res., 29, 37553758, doi:10.1029/93wr01934, 1993.

Ol'dekop, E. M.: On evaporation from the surface of river basins, Trans. Meteorol. Obs., 4, p. 200, 1911.

Pike, J. G.: The Estimation of Annual Run-off from Meteorological Data in a Traopical Climate, J. Hydrol., 2, 116-123, 1964.

Porporato, A., Daly, E., and Rodriguez-Iturbe, I.: Soil water balance and ecosystem response to climate change, Am. Nat., 164, 625632, doi:10.1086/424970, 2004.

Savenije, H. H. G.: Determination of evaporation from a catchment water balance at a monthly time scale, Hydrol. Earth Syst. Sci., 1, 93-100, doi:10.5194/hess-1-93-1997, 1997.

Schreiber, P.: Ueber die Beziehungen zwischen dem Niederschlag und der Wasserfvhrung der flvsse in Mitteleuropa, Z Meteorol, 21, 442-452, 1904.

Sivapalan, M., Yaeger, M. A., Harman, C. J., Xu, X., and Troch, P. A.: Functional model of water balance variability at the catchment scale: 1 . Evidence of hydrologic similarity and space-time symmetry, Water Resour Res, 47, W02522, doi:10.1029/2010wr009568, 2011.

Sun, F.: Study on Watershed Evapotranspiraiton based on the Budyko Hypothesis, Doctor of Engineering, Tsinghua University, 147 pp., 2007.

Thomas, H. A.: Improved methods for national water assessment, Water Resources Council, Washington, D. C., contract: WR15249270, 1-59, 1981.

Wang, D.: Evaluating interannual water storage changes at watersheds in Illinois based on long-term soil moisture and groundwater level data, Water Resour. Res., 48, WO35032, doi:10.1029/2011WR010759, 2012. 
Wang, D. and Tang, Y.: A one-parameter Budyko model for water balance captures emergent behavior in darwinian hydrologic models, Geophys. Res. Lett., 41, 4569-4577, doi:10.1002/2014GL060509, 2014.

Wang, T., Istanbulluoglu, E., Lenters, J., and Scott, D.: On the role of groundwater and soil texture in the regional water balance: An investigation of the Nebraska Sand Hills, USA, Water Resour. Res., 45, W10413, doi:10.1029/2009wr007733, 2009.

Wu, B., Yan, N., Xiong, J., Bastiaanssen, W. G. M., Zhu, W., and Stein, A.: Validation of ETWatch using field measurements at diverse landscapes: A case study in Hai Basin of China, J. Hydrol., 436, 67-80, doi:10.1016/j.jhydrol.2012.02.043, 2012.

Xiong, L. H., Yu, K. X., and Gottschalk, L.: Estimation of the distribution of annual runoff from climatic variables using copulas, Water Resour. Res., 50, 7134-7152, doi:10.1002/2013wr015159, 2014.

Yan, H., Zhan, J., Liu, B., and Yuan, Y.: Model Estimation of Water Use Efficiency for Soil Conservation in the Lower Heihe River Basin, Northwest China during 2000-2008, Sustainability, 6, 6250-6266, doi:10.3390/su6096250, 2014.

Yang, D., Sun, F., Liu, Z., Cong, Z., Ni, G., and Lei, Z.: Analyzing spatial and temporal variability of annual water-energy balance in nonhumid regions of China using the Budyko hypothesis, Water Resour. Res., 43, W04426, doi:10.1029/2006wr005224, 2007.

Yang, H., Yang, D., Lei, Z., and Sun, F.: New analytical derivation of the mean annual water-energy balance equation, Water Resour. Res., 44, W03410, doi:10.1029/2007wr006135, 2008.
Yao, Y., Liang, S., Xie, X., Cheng, J., Jia, K., Li, Y., and Liu, R.: Estimation of the terrestrial water budget over northern China by merging multiple datasets, J. Hydrol., 519, 50-68, doi:10.1016/j.jhydrol.2014.06.046, 2014.

Yokoo, Y., Sivapalan, M., and Oki, T.: Investigating the roles of climate seasonality and landscape characteristics on mean annual and monthly water balances, J. Hydrol., 357, 255-269, doi:10.1016/j.jhydrol.2008.05.010, 2008.

Zhang, L., Dawes, W. R., and Walker, G. R.: Response of mean annual evapotranspiration to vegetation changes at catchment scale, Water Resour. Res., 37, 701-708, doi:10.1029/2000wr900325, 2001.

Zhang, L., Hickel, K., Dawes, W. R., Chiew, F. H. S., Western, A. W., and Briggs, P. R.: A rational function approach for estimating mean annual evapotranspiration, Water Resour. Res., 40, W02502, doi:10.1029/2003wr002710, 2004.

Zhang, L., Potter, N., Hickel, K., Zhang, Y., and Shao, Q.: Water balance modeling over variable time scales based on the Budyko framework - Model development and testing, J. Hydrol., 360, 117-131, doi:10.1016/j.jhydrol.2008.07.021, 2008.

Zhou, S., Yu, B., Huang, Y., and Wang, G.: The complementary relationship and generation of the Budyko functions, Geophys Res. Lett., 42, 1781-1790, doi:10.1002/2015g1063511, 2015. 